\title{
Bringing science education in and out of school closer together
}

\author{
Professor Justin Dillon \\ King's College London, United Kingdom
}

Throughout the world, and for many decades, science-rich cultural institutions, such as zoos, aquaria, museums, and others, have collaborated with schools to provide students, teachers and families with opportunities to expand their experiences and understanding of science. Programmes include supplementary classroom experiences; integrated core academic curricula; student science learning communities located in afterschool, summer, and weekend programmes; teacher professional development opportunities and communities; and even district infrastructure efforts around issues such as standards and assessment development or teacher preparation. Throughout the world, these collaborations have allowed students, and also teachers, to explore, understand, and care about a wide range of natural settings, phenomena, and cultural and historical objects. They have helped students to notice, consider, and investigate relationships between human social behavior and environmental consequences. They have provided contexts, materials, rationales, and support for students and teachers to engage deeply in scientific inquiry processes of learning. These experiences-with an array of real-life settings, plants, animals, professional science communities, objects, scientific instrumentation, and current research and data-have been shown to spark curiosity, generate questions, and lead to a depth of understanding and commitment in ways that are often less possible when the same material is encountered in books or on screens. This paper draws on theoretical perspectives as well as practical examples, focusing on inquiry-based science education, to show that formal-informal collaborations fall within the core activities of both schools and organisations working in informal contexts including museums, youth programmes, and libraries. The paper argues that what is needed are more intentional and strategic deployments of resources, leading to collaborations that build on the particular affordances and strengths of different institutional types to meet shared goals of making science learning more accessible and compelling to young people in our communities.

Keywords: inquiry-based science education; school.museum collaboration; science teaching and learning 